\title{
Pelatihan Komputer Dasar Bagi Kader PKK dan Posyandu Di Desa Patikraja
}

\author{
Linda Perdana Wanti ${ }^{1}$, Eka Tripustikasari ${ }^{2}$ \\ ${ }^{1,2}$ Program Studi Teknik Informatika, STMIK Amikom Purwokerto \\ E-mail: perdanamine@gmail.com ${ }^{1}$, ekatripustikasari@gmail.com ${ }^{2}$
}

\section{INFORMASI ARTIKEL}

\section{Data artikel:}

Naskah masuk, 24 Juli 2019

Direvisi, 1 September 2019

Diterima, 1 Desember 2019

\section{Kata Kunci:}

Microsoft PowerPoint

Microsoft Word

PKK

Posyandu

Desa Patikraja

\begin{abstract}
ABSTRAK
Abstract-Empowerment of Family Welfare or often abbreviated as PKK is a movement that has been built from the center to the village and its existence and benefits have been felt by the community. This PKK activity is reflected in the 10 PKK Principal Programs, one of which is focused on health and attention specifically aimed at maternal and child health. So that an Integrated Service Post (Posyandu) was formed consisting of trained Posyandu cadres. These trained Posyandu cadres are not only seen from the way they handle maternal and child health but also must be supported by their ability to use computers in the process of recording and data collection. However, not all PKK and Posyandu Cadres, especially in villages, are adept at using computers, for example, PKK Cadres and Patikraja Village Posyandu. In fact, many cadres are new to computers and cannot use standard programs such as Microsoft PowerPoint and Microsoft Word. The goal of this community service program is to improve the capabilities and competencies of PKK Cadres and Patikraja Village Posyandu in operating computers to support good and smooth performance in terms of administration and data collection. Based on the results of the evaluation it was seen that PKK cadres and the Patikraja Village Posyandu attended the training with great enthusiasm and they were able to practice the material very well.
\end{abstract}

\begin{tabular}{l} 
Abstrak-Pemberdayaan Kesejahteraan Keluarga atau yang \\
sering disingkat menjadi PKK adalah gerakan yang telah \\
dibangun dari pusat hingga desa dan keberadaan maupun \\
manfaatnya sudah dirasakan oleh masyarakat. Kegiatan PKK \\
ini tercermin dari 10 Program Pokok PKK, yang salah satu \\
programnya terfokus pada kesehatan dan perhatian khususnya \\
ditujukan kepada kesehatan ibu dan anak. Sehingga \\
dibentuklah Pos Pelayanan Terpadu (Posyandu) yang terdiri \\
dari kader Posyandu yang terlatih. Kader Posyandu yang \\
terlatih ini tidak hanya terlihat dari cara penanganan mereka \\
terhadap kesehatan ibu dan anak namun juga harus didukung \\
oleh kemampuan mereka dalam menggunakan komputer dalam \\
proses pencatatan dan pendataan. Namun, tidak semua Kader \\
PKK dan Posyandu terutama di desa mahir menggunakan \\
komputer, contohnya Kader PKK dan Posyandu Desa \\
\hline
\end{tabular}




\section{Korespondensi:}

\section{Linda Perdana Wanti}

Program Studi Teknik Informatika, STMIK Amikom Purwokerto

Jl. Pol. Soemarto, Purwanegara, Purwokerto Utara, Kabupaten Banyumas, Jawa Tengah 53127

Telp (0281) 623321

\section{PENDAHULUAN}

Peraturan Menteri Dalam Negeri Nomor 5 Tahun 2007 menyebutkan bahwa PKK atau Pemberdayaan Kesejahteraan Keluarga merupakan gerakan masyarakat yang tumbuh dari bawah, dikelola oleh, dari dan untuk masyarakat menuju terwujudnya keluarga yang sejahtera atas kesadaran dan kemampuan keluarga itu sendiri (Republik Indonesia 2007). Untuk mewujudkannya maka dilaksanakan "Sepuluh Program Pokok PKK". Keberadaan PKK ini ditengah masyarakat sangat dirasakan manfaatnya karena PKK membangkitkan dan menggerakkan partisipasi keluarga dan masyarakat. Tim penggerak PKK ini dibentuk di semua tingkat administrasi baik di Pusat, Provinsi, Kabupaten, Kecamatan, Desa dan Kelurahan.

Pelayanan kesehatan dasar di Posyandu adalah suatu upaya untuk meningkatkan berbagai layanan yang dibutuhkan oleh masyarakat seperti perbaikan gizi, pendidikan dan perkembangan anak, peningkatan ekonomi keluarga, ketahanan pangan keluarga dan kesejahteraan sosial (Fatjrin Agustina, Ach. Rasyad 2017). Berdasarkan Surat Keputusan Bersama Mendagri/Menkes/BKKBN No.23 tahun 1985 tentang penyelenggaraan Posyandu yaitu meningkatkan kerja sama lintas sektoral antar PKK dan Posyandu. Salah satu program yang menjadi perhatian PKK adalah mengembangkan dan membina pelaksaaan kegiatan Posyandu (Sulaeman 2010). Para kader PKK dan Posyandu dituntut agar mampu memberikan pelayanan secara prima dan optimal kepada masyarakat di tempat mereka sendiri.

Pengabdian masyarakat yang sudah pernah dilakukan oleh Hernawan tentang pelatihan komputer bagi perangkat desa di kecamatan Gondangrejo kabupaten Karanganyar. Dalam pelatihan tersebut materi yang diberikan kepada perangkat desa seputar pengoperasian komputer mulai dari cara menghidupkan dan menshutdown komputer sampai dengan menjalankan program-program aplikasi yang ada di perangkat komputer (Sulistyanto 2017). Pengabdian masyarakat oleh Rahmawati dan Andika Rusli dengan sasaran pegawai KKN-PPM UKM di kota Palopo. Pada pengabdian tersebut pegawai KKN-PPM UKM diberikan pelatihan tentang tata cara pelatihan pembuatan dan pembimbingan laporan keuangan yang dimulai dengan pembuatan jurnal transaksi keuangan sampai dengan laporan akhir sesuai dengan bidang usaha yang ada pada UKM di kota Palopo (Rahmawati; and Rusli 2017).

Selanjutnya pengabdian masyarakat yang dilakukan oleh Risdiana dalam bidang teknologi informasi. Pada pengabdian kali ini Risdiana memberikan pelatihan dasar-dasar statistika kepada guru-guru di SDN Pamotan II kecamatan Porong. pelatihan yang dilakukan dengan menggunakan microsoft excel. Pelatihan ini sangat bermanfaat karena 
membantu para guru dalam pengolahan nilai siswa sampai dengan penyusunan rapor yang diterimakan setiap semester. Metode yang dilakukan ada 3 tahapan, yang pertama melakukan observasi terhadap kegiatan guru saat pengolahan nilai dan penyusunan rapor, tahap kedua penyampaian materi tentang microsoft excel yang berguna untuk membantu tugas para guru dan tahapan yang terakhir adalah membimbing para guru pada saat proses pengolahan nilai dan penyusunan nilai rapor dengan menggunakan microsoft excel (Dhewy 2018). Pelatihan tentang pengenalan android pada siswa SMK juga dilakukan oleh Agus, dkk dalam rangka pengabdian kepada masyarakat. Tujuan pelatihan ini adalah untuk mempersiapkan lulusan SMK yang akan terjun ke dunia kerja sehingga bisa berdaya saing dengan lulusan-lulusan yang lain. Manfaat penelitian ini adalah siswa SMK yang diberikan pelatihan android dapat menerapkan skill pengetahuan mereka di dunia kerja (Suryadi, Agus; Nasution, Akmal; Febrianti 2018).

Program posyandu merupakan strategi jangka panjang untuk menurunkan angka kematian bayi (infant mortality rate), angka kelahiran bayi (birth rate), dan angka kematian ibu (maternal mortality rate) turunnya (infant mortality rate, birth rate, maternal mortality rate) di suatu daerah untuk mempercepat standar keberhasilan pelaksanaan program terpandu di suatu wilayah tersebut (Sengkey and Pangemanan 2015). Peran Posyandu di tengah-tengah masyarakat yang sangat penting sebagai wadah pelayanan masyarakat yang meliputi kesehatan ibu dan balita, kesehatan lansia, maka diperlukan keterampilan dan pengetahuan kader-kader Posyandu yang mumpuni (Happinasari, Ossie; Suryandari 2017). Tidak terkecuali di Desa Patikraja Kecamatan Patikraja, Banyumas. Para Kader PKK dan Kader Posyandu Desa Patikraja ini secara berkala ditingkatkan kapasitas dan kompentensinya demi memberikan pelayanan yang optimal kepada masyarakat.

Peningkatan kapasitas dan kompetensi bagi para Kader PKK dan Kader Posyandu yang dirasa sangat perlu adalah kemampuan mereka dalam mengoperasikan komputer. Berdasarkan komunikasi dengan Kadus dan Bidan Desa, para Kader PKK dan khususnya
Kader Posyandu menyatakan bahwa peningkatan kemampuan menguasai komputer bagi para kader ini dimaksudkan untuk menunjang kinerja yang baik dan lancar dalam hal administrasi maupun pendataan.

Persoalan yang dihadapi para Kader PKK dan Posyandu Patikraja ini belum semua mengenal dan mengetahui bagaimana cara mengoperasikan komputer. Para Kader juga belum mahir dalam menggunakan programprogram standart di komputer terutama Microsoft Word dan Microsoft PowerPoint. Padahal kebutuhan akan pengusaan komputer ini diperlukan bagi para Kader PKK dan Posyandu untuk untuk menunjang kegiatan administrasi dan pendataan perkembangan kegiatan para Kader PKK dan Posyandu itu sendiri. Selain itu, tidak adanya tenaga pengajar yang mampu untuk mengajari para Kader ini agar lebih menguasai keterampilan komputer.

Berdasarkan analisis situasi dapat diidentifikasikan permasalahan mitra dalam program pelatihan keterampilan untuk membekali kompetensi anggota PKK dan kader Posyandu Desa Patikraja yaitu sebagai berikut: (1) Pelatihan keterampilan Microsoft Office khususnya Microsoft Word dan Microsoft PowerPoint. Pelatihan keterampilan di dalam Microsoft Word dan Microsoft PowerPoint diperlukan oleh kader PKK dan kader Posyandu Desa Patikraja guna membantu kader dalam melakukan kegiatan pencatatan dan administrasi data yang lebih baik; (2) Sarana dan prasarana untuk mendukung pelatihan keterampilan Microsoft Office khususnya Microsoft Word dan Microsoft PowerPoint belum ada. PKK dan Posyandu Desa Patikraja belum memiliki laboratorium komputer, akibatnya pelatihan ketrampilan yang berhubungan dengan komputer belum dapat terlaksana; (3) Tenaga pengajar belum memiliki kualifikasi untuk melakukan pelatihan keterampilan Microsoft Office khususnya Microsoft Word dan Microsoft PowerPoint. Tidak adanya tenaga pengajar yang berkualifikasi untuk mengajarkan keterampilan Microsoft Office ini menghambat dalam melakukan pelatihan Microsoft Office.

Pelatihan adalah suatu proses yang dilakukan untuk mencapai kemampuan tertentu dalam rangka membantu mencapai tujuan 
organisasi dan diperlukan guna meningkatkan efisiensi, efektivitas, serta produktivitas kerja yang terarah (Lodjo 2013).

Berdasarkan permasalahan yang telah diuraikan sebelumnya, maka beberapa solusi yang akan dilaksanakan untuk memecahkan permasalahan mitra dalam hal ini kader PKK dan kader Posyandu desa Patikraja, yaitu: (1) Menyelenggarakan keterampilan Microsoft Office khususnya Microsoft Word dan Microsoft PowerPoint yaitu berupa pelatihan ini diberikan kepada kader PKK dan kader Posyandu Desa Patikraja. Pelatihan yang difokuskan pada pelatihan Microsoft Word dan Microsoft PowerPoint; (2) Menyediakan fasilitas laboratorium komputer untuk kegiatan pelatihan Microsoft Office khususnya Microsoft Word dan Microsoft PowerPoint dengan menggunakan laboratorium komputer milik STMIK AMIKOM Purwokerto; (3) Menyediakan tenaga pengajar yang berkompeten untuk kegiatan pelatihan Microsoft Office khususnya Microsoft Word dan Microsoft Power Point. Tenaga pengajar yang terlibat dalam pelatihan ini berjumlah 2 orang dan untuk membantu kegiatan pelatihan ini pengajar.

Keberhasilan kegiatan pelatihan keterampilan komputer Micrososft Office terutama Micrososft Word dan Microsoft PowerPoint diharapkan memberi luaran kepada Mitra, yaitu Kader PKK dan Posyandu Desa Patikraja mampu mengoperasikan komputer serta memiliki keahlian dalam menggunakan Microsoft Office terutama Microsoft Word dan Microsoft Power Point.

\section{METODE PELAKSANAAN}

\subsection{Metode Penyelesaian Masalah}

Berdasarkan permasalahan yang dihadapi, penggambaran skema permasalahan, potensi, pemecahan masalah, dan target luaran kegiatan pengabdian seperti pada Gambar 1.

Tahapan kegiatan secara teknis yang akan dilakukan oleh Tim Pelaksana meliputi: (1) Koordinasi ke Kader PKK dan Posyandu Desa Patikraja Kecamatan Patikraja Kabupaten Banyumas; (2) Sosialisasi pelatihan ketrampilan kepada kader PKK dan Posyandu
Desa Patikraja; (3) Pelaksanaan pelatihan Microsoft Word dan Microsoft PowerPoint.

\section{Masalah yang Dihadapi}

1. Pelatihan keterampilan Microsoft Office khususnya Microsoft PowerPoint dan Microsoft Word

2. Sarana dan prasarana untuk mendukung pelatihan keterampilan Microsoft Office khususnya Microsoft PowerPoint dan Microsoft Word belum ada

3. Tenaga pengajar belum memiliki kualifikasi untuk melakukan pelatihan keterampilan Microsoft Office khususnya Microsoft PowerPoint dan Microsoft Word

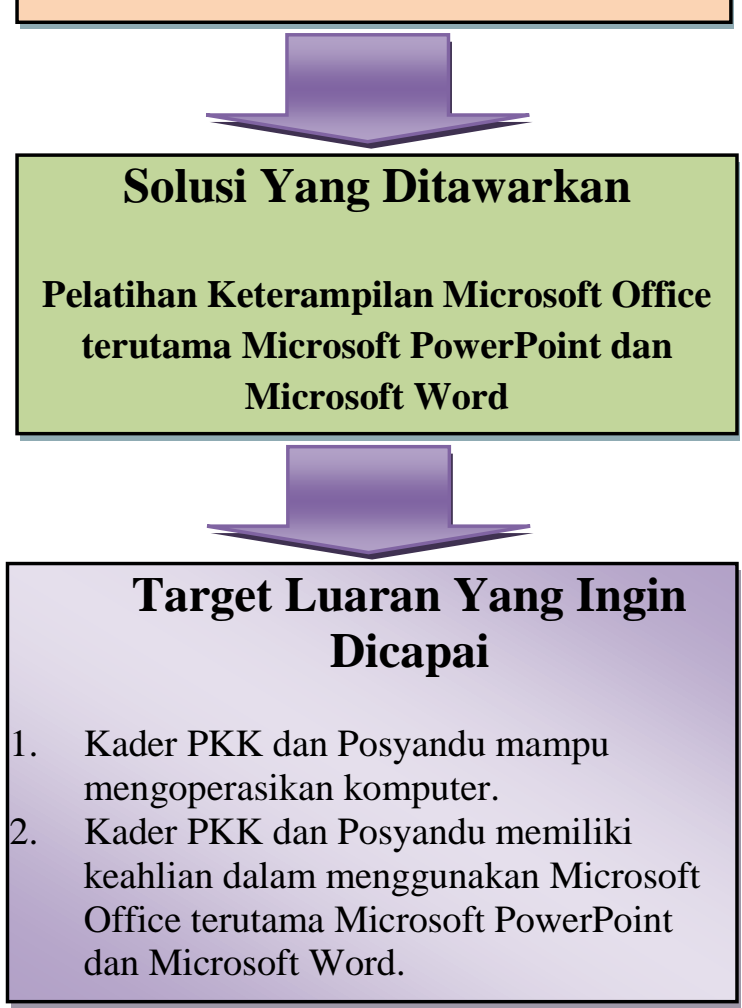

Gambar 1. Skema Masalah, Solusi dan Target Luaran

Partisipasi mitra dalam pelaksanaan program pengabdian kepada masyarakat sangat menentukan keberhasilan dan keberlanjutan program. Beberapa cara untuk mendorong mitra agar memberikan partisipasi aktif dalam pelaksanaan program pengabdian kepada masyarakat, yaitu pelibatan Mahasiswa Sebagai Trainer. Peran mahasiswa sebagai Trainer untuk khalayak sasaran program 
Tabel 1. Materi Pelatihan Microsoft Word dan Microsoft PowerPoint

\begin{tabular}{|c|c|c|c|}
\hline Hari & Waktu & Pokok Bahasan & Target \\
\hline Ke-1 & 120 menit & $\begin{array}{l}\text { Pengenalan MS. Word dan } \\
\text { MS. Power Point serta } \\
\text { pengaturan format data pada } \\
\text { MS. Word dan MS Power } \\
\text { Point }\end{array}$ & $\begin{array}{l}\text { Diharapkan peserta pelatihan mampu } \\
\text { membuat naskah sederhana dalam format } \\
\text { Word dan membuat naskah presentasi } \\
\text { sederhana dengan MS. Power Point }\end{array}$ \\
\hline $\mathrm{Ke}-2$ & 120 menit & $\begin{array}{l}\text { Bekerja dengan fungsi pada } \\
\text { MS. Word dan MS. Power } \\
\text { Point }\end{array}$ & $\begin{array}{l}\text { Diharapkan peserta pelatihan mampu } \\
\text { memahami dan bekerja fungsi-fungsi yang } \\
\text { ada pada MS. Word dan MS. Power Point }\end{array}$ \\
\hline $\mathrm{Ke}-3$ & 120 menit & $\begin{array}{l}\text { Membuat grafik dan } \\
\text { pengaturan naskah presentasi } \\
\text { pada MS. Word dan MS. } \\
\text { Power Point }\end{array}$ & $\begin{array}{l}\text { Diharapkan peserta pelatihan mampu } \\
\text { membuat grafik dan mengatur } \\
\text { presentasi pada MS. Word dan MS. Power } \\
\text { Point }\end{array}$ \\
\hline
\end{tabular}

Tabel 2. Tentor Pelatihan Microsoft Word dan Microsoft PowerPoint

\begin{tabular}{|c|c|c|c|}
\hline Tanggal & Sub Pokok Bahasan & Lab. & Tentor \\
\hline \multirow{7}{*}{$\begin{array}{l}15 \text { Maret } \\
2015\end{array}$} & a. Mengenal sekilas program MS. word dan MS. & Lab & Linda \\
\hline & power point & Pemrograman & Perdanawanti \\
\hline & b. Memahami cara menulis naskah dan membuat & & Eka Tripustikasari \\
\hline & $\begin{array}{l}\text { naskah presentasi dengan MS. word dan MS. } \\
\text { power point }\end{array}$ & & \\
\hline & c. Mengatur border dan background & & \\
\hline & $\begin{array}{l}\text { d. Mengubah naskah yang ada di word dan } \\
\text { mengatur desain naskah presentasi di MS. } \\
\text { power point }\end{array}$ & Lab Aplikası & \\
\hline & e. Mengatur tampilan halaman & & \multirow{6}{*}{$\begin{array}{l}\text { Linda } \\
\text { Perdanawanti } \\
\text { Eka Tripustikasari }\end{array}$} \\
\hline \multirow{5}{*}{$\begin{array}{l}16 \text { Maret } \\
2015\end{array}$} & a. Membuat surat di MS word & $\mathrm{Lab}$ & \\
\hline & b. Meng-copy surat & Pemrograman & \\
\hline & $\begin{array}{l}\text { c. Menyisipkan gambar ke dalam naskah } \\
\text { presentasi }\end{array}$ & & \\
\hline & $\begin{array}{l}\text { d. Mengatur desain naskah prsentasi di MS. } \\
\text { power point }\end{array}$ & Lab Aplikasi & \\
\hline & $\begin{array}{l}\text { e. Membuat tabel dan meletakkannya di tengah } \\
\text { naskah }\end{array}$ & & \\
\hline \multirow{8}{*}{$\begin{array}{l}17 \text { Maret } \\
2015\end{array}$} & f. Menyisipkan tabel ke dalam naskah presentasi & & \multirow{8}{*}{$\begin{array}{l}\text { Linda } \\
\text { Perdanawanti } \\
\text { Eka Tripustikasari }\end{array}$} \\
\hline & a. Membuat grafik & Lab & \\
\hline & b. Memodifikasi grafik & Pemrograman & \\
\hline & c. Menandai data yang akan dicetak & \multirow{5}{*}{ Lab Aplikasi } & \\
\hline & d. Penggunaan print preview & & \\
\hline & e. Mengatur halaman & & \\
\hline & f. Mengatur margin & & \\
\hline & g. Menambahkan header dan footer & & \\
\hline
\end{tabular}

sangat penting. Mahasiswa sebagai Trainer pelatihan untuk pihak yang terkait dengan program pelatihan keterampilan komputer. Hal ini menunjukkan bahwa peran mahasiswa mampu memunculkan citra bahwa kegiatan ini penting sehingga apresiasi khalayak sasaran terhadap program sangat tinggi. 
Pemberian materi pelatihan Microsoft Word dan Microsoft PowerPoint kepada para kader PKK dan Posyandu mampu meningkatkan keinginan untuk belajar dan keinginan untuk menambah wawasan dan ilmu pengetahuan di bidang komputer dan teknologi informasi. Materi yang diberikan untuk pelatihan pengoperasian Microsoft Office adalah seperti pda Tabel 1.

\section{HASIL DAN PEMBAHASAN 3.1 Peserta Pelatihan}

Pelaksanaan kegiatan pengabdian masyarakat dengan memberikan pelatihan Microsoft Word dan Microsoft PowerPoint pada Maret 2015 yang diikuti oleh 16 orang Kader PKK dan Posyandu Desa Patikraja, telah memperoleh hasil capaian, yaitu :

\subsection{Lokasi dan Waktu Pelatihan}

Pelatihan Microsoft Office Word dan Microsoft PowerPoint ini dilaksanakan pada tanggal 15 Maret 2015 di Laboratorium Komputer STMIK AMIKOM Purwokerto. Tim pelaksana dilibatkan dalam kegiatan belajar mengajar sebagai tentor dan mendapat bantuan dari asisten praktikum. Tiap 1 sesi materi berdurasi 120 menit, dengan jam mulai pelaksanaan pukul 09.00 WIB. Tabel 2 menjelaskan tanggal pelaksanaan, pokok bahasan, tentor, dan asisten praktikum pada materi Microsoft Office.

\subsection{Pelaksanaan Pelatihan}

Kegiatan pelatihan Microsoft Word dan Microsoft PowerPoint diikuti oleh 16 orang Kader PKK dan Posyandu Desa Patikraja. Presensi kehadiran siswa tiap pertemuan kami sertakan datanya pada bagian lampiran laporan kemajuan ini. Gambar 2, Gambar 3, gambar 4 dan Gambar 5 merupakan dokumentasi kegiatan pelatihan Microsoft Word dan Microsoft PowerPoint.

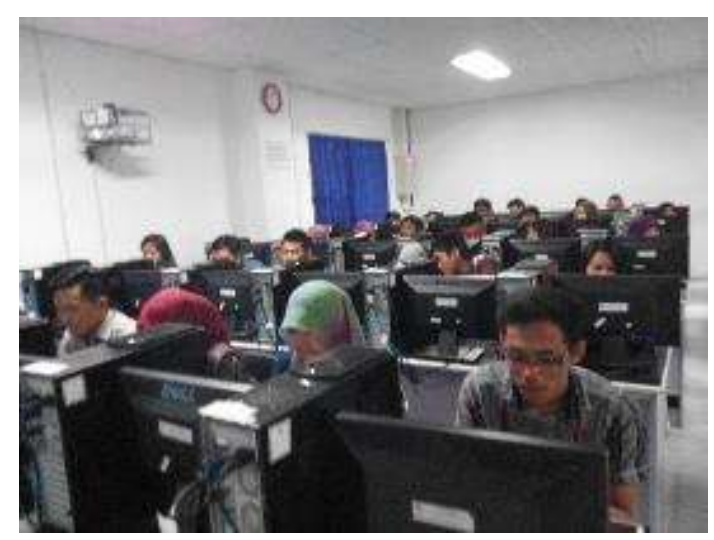

Gambar 2. Suasana Pemberian Materi Pelatihan

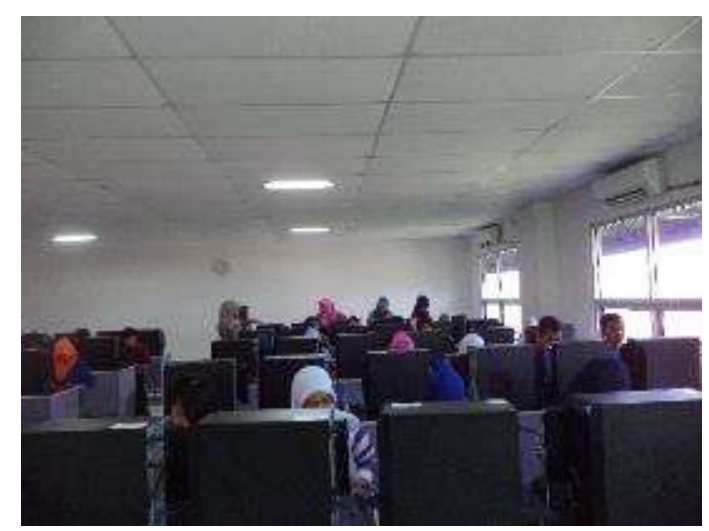

Gambar 3. Proses Pembelajaran Materi Ms. Word

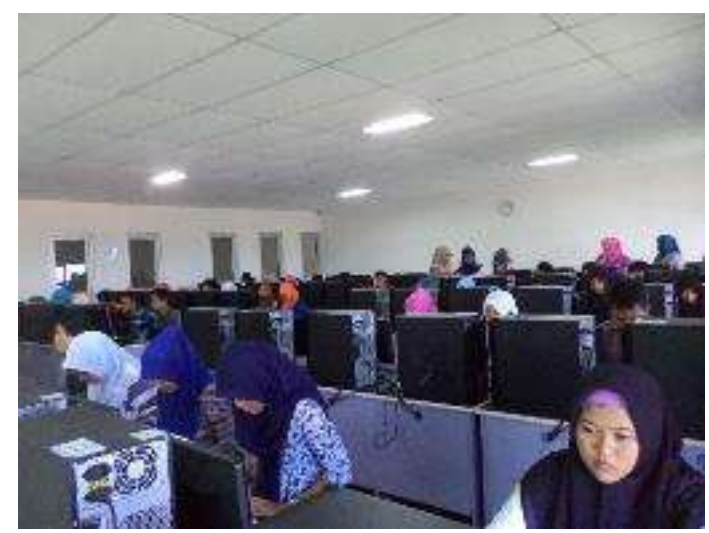

Gambar 4. Proses Pembelajaran Materi Ms. Power Point 


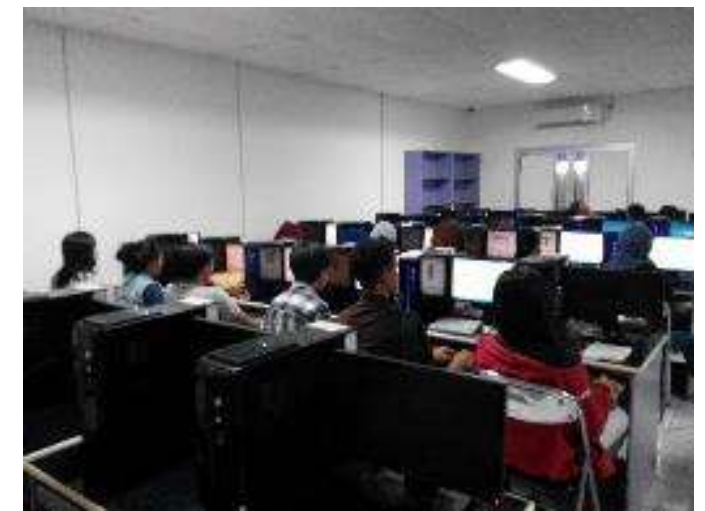

Gambar 5. Pendampingan Pelatihan

\section{KESIMPULAN}

Setelah kegiatan pengabdian kepada masyarakat ini dilakukan, mulai dari tahap koordinasi, sosialisasi dan pelatihan Microsoft Word dan Microsoft Power Point dengan pihak PKK dan Posyandu Patikraja telah usai, maka dapat ditarik beberapa kesimpulan kegiatan pengabdian masyarakat terlaksana sesuai dengan tujuan dan rencana. Kegiatan pengabdian masyarakat ini mendapat sambutan yang baik dari Kader PKK dan Posyandu Desa Patikraja. Pengetahuan dan pemahaman Kader PKK dan Posyandu Desa Patikraja mengenai Microsoft Word dan Microsoft Power Point meningkat setelah mengikuti kegiatan pelatihan.

Berdasarkan kegiatan pengabdian kepada masyarakat yang telah dilakukan, maka terdapat beberapa saran terhadap pengembangan kegiatan pengabdian masyarakat selanjutnya. Beberapa saran pengembangan tersebut, yaitu kegiatan pengabdian masyarakat seperti ini hendaknya dapat dilanjutkan dan disebarluaskan kepada kelompok PKK dan Posyandu yang lain di wilayah Banyumas dan sekitarnya. Jenis materi keterampilan komputer dapat ditambah lagi yang penyesuaiannya mengikuti kebutuhan di lingkungan PKK dan Posyandu seperti pelatihan Microsoft Office lainnya seperti Excel dan penggunaan internet.

\section{DAFTAR PUSTAKA}

Dhewy, Risdiana Chandra. 2018. "Pelatihan Dasar-Dasar Statistika Dengan Menggunakan Aplikasi Microsoft Excel Di Sdn Pamotan Ii Kecamatan Porong."
Jurnal PADI - Pengabdian mAsyarakat Dosen Indonesia 1(1): 36-40.

Fatjrin Agustina, Ach. Rasyad, Sri Wahyuni. 2017. "Kesiapan Kader Dalam Melaksanakan Pelayanan Posyandu." Universitas Negeri Malang, Volume 2 Nomor 2, Desember 2017: 157-162: 15762.

Happinasari, Ossie; Suryandari, Artathi Eka. 2017. "Jurnal Ilmu Kebidanan Dan Kesehatan (Journal of Midwifery Science and Health) Akbid Bakti Utama Pati." 8(1): 1-15.

Lodjo, Fernando Stefanus. 2013. "Pengaruh Pelatihan, Pemberdayaan Dan Efikasi Diri Terhadap Kepuasan Kerja." Jurnal EMBA 1(3): 747-55.

Rahmawati;, and Andika Rusli. 2017. "Pelatihan Dan Pembimbingan Pembuatan Sistem Laporan Keuangan Sederhana Pada Ukm Di Kota Palopo." Jurnal Akuntansi 3(1): 35-38.

Republik Indonesia. 2007. Peraturan Menteri Dalam Negeri Nomor 5 Tahun 2007 Peraturan Menteri Dalam Negeri Nomor $5 \quad$ Tahun 2007. http://joi.jlc.jst.go.jp/JST.Journalarchive/ materia1994/46.171?from=CrossRef.

Sengkey, Sriyatty W, and G D Kandou J M Pangemanan. 2015. "Analisis Kinerja Kader Posyandu Di Puskesmas Paniki Kota Manado Performance Analysis of Cadres Posyandu in Puskesmas Paniki Manado." Jikmu 5(2b): 491-502.

Sulaeman, Endang Sutisna. 2010. "Revitalisasi Program Keterpaduan Kb- Kesehatan ( Posyandu ) Di Era Desentralisasi Suatu Keniscayaan." Journal of Rural and Development I(2): 89-103.

Sulistyanto, Hernawan. 2017. "Pakom Pelatihan Pengoperasian Komputer Bagi Perangkat Desa Di Kecamatan Gondangrejo Kabupaten Karanganyar." Warta LPM 20(2): 111.

Suryadi, Agus; Nasution, Akmal; Febrianti, Eka Lia. 2018. "Pada Siswa Smk Negeri 1 Air Joman-Kisaran." Jurnal Pengabdian Kepada Masyarakat) Royal ISSN 1(2): 1-4. 